\title{
Implementing the Spiritual Leadership Model in the Healthcare Industry in Iran
}

\author{
Mandana Abdizadeh ${ }^{1} \&$ Mohsen Malekalketab Khiabani ${ }^{1}$ \\ ${ }^{1}$ International Business School, University Technology Malaysia, Malaysia \\ Correspondence: Mandana Abdizadeh, International Business School, University Technology Malaysia, 54100, \\ Kuala Lumpur, Malaysia. E-mail: abmandana@gmail.com
}

Received: July 28, 2014

Accepted: September 1, $2014 \quad$ Online Published: October 22, 2014

doi:10.5539/ijbm.v9n11p92

URL: http://dx.doi.org/10.5539/ijbm.v9n11p92

\begin{abstract}
The purpose of the present research is to test the spiritual leadership model in the Iranian healthcare industry. The research takes a quantitative approach involving the distribution of 143 questionnaires to different professionals in healthcare centers in Tehran, Iran. Spiritual leadership creates an intrinsic motivation to achieve organizational outcomes. It is a function of seven dimensions: vision, hope/faith, altruistic love, meaning/calling, membership, commitment, and productivity. The authors conduct simple bivariate correlation tests, as well as linear standard and stepwise regression analyses. The findings support the notion that each dimension of spiritual leadership has a positive relationship with spiritual leadership. Among the dimensions, membership (beta coefficient $=.890$ ) is the most remarkable. This paper is useful for managers and academics. It can be used by managers of Iranian healthcare centers to motivate their employees through spiritual leadership and its various components. Furthermore, the model of this study can be implemented in the Iranian healthcare industry and hopefully in other industries.
\end{abstract}

Keywords: spiritual leadership, healthcare industry, Iran

\section{Introduction}

In the last century, due to the universal competitive environment, the need for organizational change has been considered more than ever. With the aim of achieving such change, organizational leaderships are considered bymost organizations. Leadership is an art by which a person can influence others to direct their endeavors towards attaining organizational goals. The main driver in an organization is human resources, and the role of human resources is critical in achieving organizational goals. Hence, good leadership can be beneficial for both employees and the organization.

Fry (2003) states that spiritual leadership creates intrinsic motivation through vision, hope/faith, and altruistic love, which leads to spiritual survival through meaning/calling and membership. Fairholm (1996) believes that spiritual leaders help followers to develop inspiring vision and mission statements that foster higher levels of organizational commitment and effectiveness. Similarly, Nelson (2008) mentions that spiritual leadership can help employees find vision, value, meaningful work, and specific goals.

Many studies have been conducted on spiritual leadership. One of the most important is arguably the study conducted by Fry (2003). In their research, spiritual leadership is defined as a causal leadership model designed to create an intrinsically motivated. They consider spiritual leadership theory as having seven dimensions or, in other words, being a function of seven dimensions: vision, hope/faith, and altruistic love (three dimensions of spiritual leadership); meaning/calling and membership (two dimensions of spiritual survival); and commitment and productivity.

The authors of this research support the research model used in the study by reviewing the literature regarding spiritual leadership, its dimensions and the theories that support the relationships among them. Next, the authors test the model in the Iranian healthcare industry through collecting employee data from different healthcare centers in Tehran (the capital of Iran). The findings show significant results related to positive relationship between spiritual leadership and each of its dimensions in the healthcare industry in Iran. Also, major conclusions have significant managerial implications for managers in the Iranian healthcare industry, and academic benefits for researchers who are concerned about spiritual leadership and its dimensions. 


\section{Literature Review}

\subsection{Past Studies Relevant to Spiritual Leadership}

Fry's (2003. p. 2) defines spiritual leadership as "comprising the values, attitudes, and behaviors that are necessary to intrinsically motivate one's self and others so that they have a sense of spiritual survival through calling and membership." Furthermore, according to Semercioz (2011), spiritual leadership is not a tool but is a characteristic of a leader.

Although Fry's (2003) definition of spirituality is comprehensive, other definitions are also important. Nelson (2008) explains that spiritual leadership makes employees have a holy vision and engage in value-based, cooperative working. Spiritual leadership makes the ethical requirements of followers clear and builds strong and deep relationships (Fairholm, 1996).

Indeed, spiritual leaders can increase employee motivation in terms of encouraging employees to live meaningfully and purposefully. According to Yaghoubi, Moloudi, and Banihashemi (2010), spiritual leaders develop committed and motivated employees by creating sublime spirituality insights and cultural contexts according to universal human values. According to Fry (2003), the goal of spiritual leadership is to develop an organizational vision and values in line with specific strategies, as well as to increase the power of individuals and teams. This can lead to improved commitment and productivity among employees.

Overall, spirituality in the workplace is important and necessary because its benefits can be found in the internal and external environments of the organization, such as encouraging employees to be responsible, committed, and empowered both inside and outside of the organization (Geijsel, 2003).

Fry (2003) examined leadership as providing a motivation to change and also reviewed motivation-based leadership theories. He notes the accelerating call for spirituality in the workplace, describes the universal human needfor spiritual survival through calling and membership, and distinguishes between religion and spirituality. By incorporating calling and membership as two key follower needs for spiritual survivals, spiritual leadership theory includes religious/ethics-based and value-based approaches to leadership. Finally, he discusses the process of organizational development and transformation through spiritual leadership. He gives a causal model of spiritual leadership that incorporates theories of intrinsic motivation, vision, hope/faith, and altruistic love. The model also incorporates spiritual survival across three levels; as such survival can positively affect organizational commitment and productivity.

In another study, Fry (2005) extended his spiritual leadership theory by exploring the concept of positive human health and well-being through recent developments in workplace spirituality, character ethics, positive psychology, and spiritual leadership. The purpose of this study was to extend spiritual leadership theory as a predictor of ethical and spiritual well-being, as well as corporate social responsibility. He argues that these areas provide an indication of the values, attitudes, and behaviors necessary for positive human health and well-being. In fact, his review extends the causal impact of spiritual leadership to ethical and spiritual well-being (manifested through joy, peace, and serenity) at the personal level and corporate social responsibility at the strategic and empowered team levels.

Malone and Fry (2003) measured three dimensions of spiritual leadership, two dimensions of spiritual survival, and the factors of organizational commitment and productivity using survey questions developed especially for research in spiritual leadership theory. The items' validity was discussed with practitioners, and the items had been pretested and validated in other studies and samples. According to the authors, spiritual leadership is a function of seven dimensions: vision, hope/faith, altruistic love, meaning/calling, membership, organizational commitment, and productivity.

By reviewing the above literature, authors of this research conclude that spiritual leadership is a function of seven dimensions as mentioned above.

\subsection{Background of Spiritual Leadership Theory}

Since World War II, many researchers have introduced different theories of leadership that focus on how to motivate followers. These theories include path-goal leadership, charismatic leadership, transformational leadership, and spiritual leadership.

Based on Pfeffer et al. (2003), it seems that there is significant overlap between management activities, survival spirituality, spirituality in the workplace, and motivation-based leadership theories. It appears that spiritual leadership theory should consider both workplace spirituality components and survival spirituality. Thus, spiritual leadership theory should include all components of spirituality in the workplace and dimensions of survival spirituality according to a framework of leadership theory based on motivation (Fry, 2003). According to the 
motivation-based leadership theories, there is a direct relationship between spiritual leadership and each of its dimensions (Fry, 2003).

Spirituality at work improves commitment and productivity. In fact, the basic needs of leaders and followers are merged by spiritual leadership to develop survival spirituality, which results in high commitment and productivity (Fry, 2003). It can be said that spiritual leadership involves the values that are necessary for the intrinsic motivation of a person, which gradually affects their behavior and ultimately leads to a sense of spiritual survival by calling and membership. Fry (2003) implies that spiritual leadership fundamentally involves:

1) Producing an organizational vision in which members have a sense of calling, believe their work is meaningful, and perceive that they have the ability to make a difference.

2) Developing a socio-organizational culture according to altruistic love so that both leaders and followers have a sense of care, concern, and appreciation not only for themselves but also for others. This creates a feeling of being part of an enterprise and receiving recognition and appreciation from a larger community.

\subsection{Research Gap}

In view of the literature review, it can be deduced that spiritual leadership creates intrinsic motivation among employees, which creates benefits for both employees and the organization. Based on the literature review, lack of study has yet tested the spiritual leadership model in the Iranian healthcare industry. Therefore, this research tests the model used in this study in the Iranian healthcare industry.

\subsection{Research Model}

The model of this study, which is the relationship between spiritual leadership and its dimensions, is based on the literature review of point number 2.1, while the dimensions of spiritual leadership are based on model developed by Fry (2003).

The following figure shows the model of the present research:

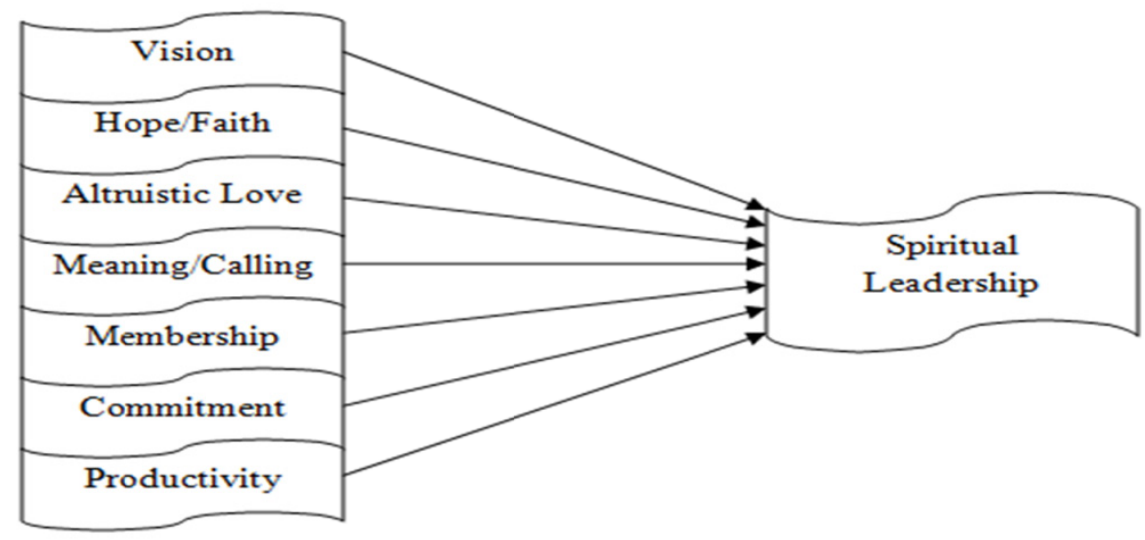

Figure 1. Model of the research (based on Fry, 2003)

\subsection{Formulation of Research Questions}

Based on the research model illustrated in Figure 1, the research questions (RQs) of this research are formulated as follows:

RQ1: Is there a relationship between vision and spiritual leadership in the Iranian healthcare industry?

RQ2: Is there a relationship between hope/faith and spiritual leadership in the Iranian healthcare industry?

RQ3: Is there a relationship between altruistic love and spiritual leadership in the Iranian healthcare industry?

RQ4: Is there a relationship between meaning/calling and spiritual leadership in the Iranian healthcare industry?

RQ5: Is there a relationship between membership and spiritual leadership in the Iranian healthcare industry?

RQ6: Is there a relationship between commitment and spiritual leadership in the Iranian healthcare industry?

RQ7: Is there a relationship between productivity and spiritual leadership in the Iranian healthcare industry? 
RQ8: Which one of the spiritual leadership dimensions is the most important for spiritual leadership in the Iranian healthcare industry?

\subsection{Research Objective}

The main objective of this research is to test the spiritual leadership model introduced by Fry in 2003 in the Iranian healthcare industry. To achieve this objective, answers to all the RQs are needed. Furthermore, the authors of this research intend to clarify the most significant dimension of spiritual leadership among the seven defined dimensions.

Therefore, the supporting objectives are as follows:

1) To test whether there is a positive relationship between vision and spiritual leadership in the Iranian healthcare industry.

2) To test whether there is a positive relationship between hope/faith and spiritual leadership in the Iranian healthcare industry.

3) To test whether there is a positive relationship between altruistic love and spiritual leadership in the Iranian healthcare industry.

4) To test whether there is a positive relationship between meaning/calling and spiritual leadership in the Iranian healthcare industry.

5) To test whether there is a positive relationship between membership and spiritual leadership in the Iranian healthcare industry.

6) To test whether there is a positive relationship between commitment and spiritual leadership in the Iranian healthcare industry.

7) To test whether there is a positive relationship between productivity and spiritual leadership in the Iranian healthcare industry.

8) To identify the most significant dimension of spiritual leadership in the Iranian healthcare industry.

\subsection{Spiritual Leadership Dimensions}

In order to better understand the spiritual leadership dimensions and their relation to spiritual leadership, the following section explains briefly each dimension of spiritual leadership as proposed by Fry (2003).

\subsubsection{Vision}

The role of vision has been highlighted due to the set of factors that make businesses become more competitive. Reviewing the literature on leadership has shown that vision was seldom applied before the 1980s (Fry, 2003). Since then, due to increased global business competition, the intense development of technology, and rapid change from old to new strategies, the leaders of organizations have paid special attention to vision in order to be more successful in the global market place (Conger, 1999). In leadership, vision has a particular place because it defines the main goal of an organization (Chegini \& Nezhad, 2012; Fry, 2003; Conger, 1999).

In fact, the vision of an organization defines the organizational goals. Fry (2003) indicates that corporate vision involves stating where the organization would like to be in the future. In other words, vision defines the future prospects of an organization. According to Strange and Mumford (2005), vision is a collection of notions that define an ultimate goal, which in turn defines individuals' actions and reactions.

Based on the studies of Fry (2003) and Strange and Mumford (2005), vision in spiritual leadership incorporates three goals:

1) Making the process of alignment and changes clear.

2) Making all aspects of decision-making easier in order to achieve the vision.

3) Assisting in the rapid and effective alignment of anything needed to realize the vision.

Indeed, spiritual leaders create a vision for the future of an organization and its staff, who subsequently believe they can help to realize the vision. In addition, the internal motivation of employees causes them to increase their efforts. According to Conger (1999), the vision of an organization can be a factor in enhancing motivation among followers. Therefore, by creating a vision and common values, spiritual leaders can provide a base for individual and organizational satisfaction.

\subsubsection{Hope/Faith}

Although hope and faith are two words that are used together in spiritual leadership studies, there is a very fine distinction between them. Some studies have asserted that hope is less important than faith (e.g. Fry \& Nisiewicz, 2013; Fry, Hannah, Noel, Walumbwa, 2011; Fry, 2003). According to Fry (2003), hope is the expectation that 
wishes will be realized, adding assurance to hope results in faith (Fry \& Nisiewicz, 2013). Hope and faith are two foundations of the belief that all the goals of the organization, such as the organizational vision and mission, will be achieved (Fry, 2003).

Hence, we can understand that spiritual leadership in organizations helps to form and improve employees' spiritual beliefs and faith at work. In turn, these aspects act as inner drivers for employees to improve themselves so that they perform their duties and responsibilities in the best possible ways, which ultimately increases the accountability of staff.

\subsubsection{Altruistic Love}

It is clear that vision is an important and considerable concept in the organizational literature. In fact, the organizational culture is defined through the organizational vision. Moreover, culture involves a set of core values not only regarding oneself but also others. Many studies have pointed out that altruistic love is a crucial value in organizational culture (Fry et al, 2011; Aydin \& Ceylan, 2009; Fry, 2003). Altruistic love has a specific definition in spiritual leadership theory: it is a sense of being whole and content presented through attention, affect, solicitousness, and gratefulness for us and others (Fry, 2003). Altruistic love for others makes a person emotionally strong.

Both medical and psychological sciences justify the notion that love can be a powerful factor in conquering four essential types of harmful feelings (Snyder \& Ingram, 2000):

1) Fear: concern, distress, misgivings, and so on.

2) Wrath: displeasure, discontentment, enmity, sense of bitterness, covetousness, and so on.

3) Sense of disability and not succeeding: helplessness, weakness, inability to help, unhappiness, sense of being sinful, and so on (all of which can lead to dysthymia).

4) Arrogance: bias, extensive pride, egotism, and so on.

Such harmful feelings arise from a fear of the loss of a valuable thing that we already have or a fear that we are unable to earn what we deserve (Fry, 2003). Freeman (2011) believes that leaders are able to encourage their followers to love others and thus control and conquer their fears, which in turn encourages followers to perceive such leaders as effective leaders. According to Fry and Nisiewicz (2013), spirituality guides us to live with peace and tranquility and accept our true selves, without an urge to control everything to satisfy our selfish wants.

Thus, implementing spiritual leadership by promoting a culture of altruistic love causes people to have a deep interest in and respect for themselves and their lives, as well as establish good relationships with others. This means that leaders should pay attention to the needs and interests of their staff and encourage staff development towards the fulfillment of their needs.

\subsubsection{Meaning/Calling}

In Fry's (2003) theory of spiritual leadership, the concept of meaning refers to whether organizational members believe that the jobs they do are important and meaningful for them and make a difference in people's lives. By contrast, calling is conceptualized as work performed out of a strong sense of inner direction and divine inspiration to do morally responsible work. Calling refers to the experience of transcendence or how one makes a difference through service to others. Through engaging in such work, the individual derives meaning and purpose from their life (Fry et al., 2011). According to Giacalone and Jurkiewicz (2003), people have the intrinsic drive and motivation to learn and find meaning in their work and to be a member of a group in which they feel valued for their contribution to the group's performance. It is therefore believed that meaning and calling have an intertwined relationship in the context of spirituality.

\subsubsection{Membership}

It is a fact that people like to belong to part of a crucial and larger group. Reave (2005) states that employees like to work in an environment where the leaders realize and admire their contributions. In this way, employees have a sense of being appreciated by the organization.

According to Yusof (2011), membership is defined as an employee's understanding of the organization and their sense of being appreciated. In confirmation of this, Fry (2003) declares that organizational leaders must be able to create a strong organizational culture in which both leaders and followers are concerned and responsible for themselves and others. He further states that such a culture can produce feelings of membership and being recognized and admired. 
Thus, spiritual leadership in organization gives employees a sense of being important from the view of organization and other colleagues (membership). In fact, this sense of membership causes a friendly and confident environment to develop between colleagues and facilitates relationships between leaders and employees.

\subsubsection{Commitment}

Yusof (2011) claims that one of the key factors in the success of any organization is having committed staff who engage in appropriate activities. The significant impact of spiritual leadership on organizational commitment has been found in many spiritual leadership studies as indicate in the following reviews. Spiritual leaders motivate employees to increase empowerment and organizational commitment (Yaghoubi et al, 2010). In addition, suitable leadership techniques can lead to increased job satisfaction among employees, which can promote organizational commitment and increased utility (Fry, 2003). According to Usman and Danish (2010), spiritual leadership causes increased employee loyalty and commitment to the organization.

It can be concluded that spiritual leadership creates a sense of identification, loyalty, and dependency with the organization by developing organizational commitment and a desire to remain in the organization.

\subsubsection{Productivity}

Employee productivity refers to how productive an employee is for an organization (Bodla et al., 2013). Employees who have hope/faith in the organization's vision and who experience calling and membership will engage in actions in pursuit of the vision to improve continuously and be more productive (Fry \& Matherly, 2006).

Fry (2003) points out that leadership plays a role in enhancing job satisfaction and subsequent productivity. Nelson (2008) states that spiritual leadership is associated with increased productivity. Also, Giacalone and Jurkiewicz (2003) indicate that workplace spirituality not only has personal outcomes but also delivers improved productivity.

Based on the discussions in these sections, the benefits of spirituality in the workplace have an important impact on both employees and organizations. Hence, the impact of spiritual leadership on organizations cannot be ignored.

\section{Research Methodology}

\subsection{Quantitative Approach}

The technique used in this research is quantitative, involving the distribution of questionnaires. There were some difficulties in distributing the questionnaires because the selected employees did not like to reveal their personal thoughtsor to take time out to fill in the questionnaires. Furthermore, the process of getting permission from some managers was difficult. Eventually, 143 questionnaires were distributed at random among different occupational groups of healthcare centers, like nurses, managers, doctors, and others, as well as among participants with different educational backgrounds (diploma and below, Bachelor's, Master's, and $\mathrm{PhD}$ ).

\subsection{Questionnaire Design}

The research model of this study is based on Fry's (2003) model. Fry's (2003) spiritual leadership measurement scale has 33 items across seven dimensions: vision, hope/faith, altruistic love, meaning/calling, membership, commitment, and productivity. Vision, hope/faith, and membership have five items each; meaning/calling and commitment have four items each; productivity has three items; and altruistic love has seven items.

\subsection{Data Validation Method}

The present research is based on a quantitative approach involving the distribution of questionnaires and the analysis of data using IBM SPSS Version 18. SPSS is a software package that is used for conducting different kinds of statistical tests (Coakes \& Steed, 2009).

In order to validate the data of this research, a pilot test is first conducted in order to ensure the reliability of the questionnaire in the Iranian healthcare industry. Second, to answer the RQs, linear simple bivariate correlation tests are conducted. Next, linear standard regression analysis is run to elucidate the overall relationship between spiritual leadership and its dimensions. Additionally, linear stepwise regression analysis is conducted in order to identify the most salient dimension of spiritual leadership.

\subsection{Reliability Tests}

In this research, a reliability test has been performed to find out the Cronbach's alpha for each dimension of spiritual leadership, and the spiritual leadership scale separately. Cronbach's alpha values have been used to check whether the questionnaire is reliable or not. 
The Cronbach's alpha value for spiritual leadership scale is .954 . Hence, it can be stated that the questionnaire has sufficient reliability to conduct this study in the Iranian healthcare industry. The Cronbach's alpha values are shown in Table 1.

Table 1. Reliability tests

\begin{tabular}{lll}
\hline Dimension & Cronbach's alpha value & N \\
\hline Vision & .915 & 5 \\
Hope/Faith & .894 & 5 \\
Altruistic Love & .879 & 7 \\
Meaning/Calling & .912 & 4 \\
Membership & .874 & 5 \\
Commitment & .778 & 4 \\
Productivity & .821 & 3 \\
Spiritual Leadership & .954 & 33 \\
\hline
\end{tabular}

\section{Results}

In this step, three different tests have been conducted. These tests are simple bivariate correlation tests, linear standard regression analysis, and stepwise regression analysis for spiritual leadership and its seven dimensions.

The correlation analysis between each dimension of spiritual leadership and spiritual leadership has demonstrated that there is a positive relationship between each dimension and spiritual leadership. Table 2 contains information related to the correlation tests between spiritual leadership and its dimensions.

Table 2. Correlation tests for spiritual leadership and its dimensions

\begin{tabular}{llllllll}
\hline & Vision & Hope/Faith & $\begin{array}{l}\text { Altruistic } \\
\text { Love }\end{array}$ & Meaning/Calling & Membership & Commitment & Productivity \\
\hline $\begin{array}{l}\text { Spiritual } \\
\text { Leadership }\end{array}$ & $\begin{array}{l}\mathrm{R} \\
0.718\end{array}$ & $\mathrm{R}=0.693$ & $\mathrm{R}=0.878$ & $\mathrm{R}=0.524$ & $\mathrm{R}=0.890$ & $\mathrm{R}=0.439$ & $\mathrm{R}=0.769$ \\
$\mathbf{N}$ & 143 & 143 & 143 & 143 & 143 & 143 & 143 \\
\hline
\end{tabular}

Note. Pearson's correlation is significant at the 0.01 level (1-tailed).

In order to answer the RQs, standard regression analysis has been performed. This test shows that all of the dimensions have positive coefficient beta values, which answers the first seven questions. Table 3 highlights the results of the standard regression analysis for spiritual leadership and its dimensions.

Table 3. Standard regression analysis for spiritual leadership and its dimensions

\begin{tabular}{|c|c|c|c|c|c|c|}
\hline \multirow[t]{2}{*}{ Mode } & & \multicolumn{2}{|c|}{ Unstandardized Coefficients } & \multicolumn{3}{|c|}{ Standardized Coefficients } \\
\hline & & B & Std. Error & Beta & $\mathbf{t}$ & Sig. \\
\hline \multirow[t]{8}{*}{1} & (Constant) & $-1.917 \mathrm{E}-15$ & .000 & & . & . \\
\hline & Vision & .152 & .000 & .231 & . & . \\
\hline & Hope/Faith & .152 & .000 & .216 & . & . \\
\hline & Altruistic Love & .212 & .000 & .267 & . & . \\
\hline & Meaning/Calling & .121 & .000 & .101 & . & . \\
\hline & Membership & .152 & .000 & .214 & . & . \\
\hline & Commitment & .121 & .000 & .210 & . & . \\
\hline & Productivity & .091 & .000 & .148 & . & . \\
\hline
\end{tabular}


In order to answer RQ8, stepwise regression analysis has been conducted to determine the dimension of spiritual leadership that is most significant. From the results, it is clear that membership (with a beta coefficient of 0.890) is the most remarkable dimension among the spiritual leadership dimensions. Therefore, RQ8 has been answered. Table 4 contains the information related to the stepwise regression analysis for spiritual leadership and all of its dimensions.

Table 4. Stepwise regression analysis for spiritual leadership and its dimensions

\begin{tabular}{|c|c|c|c|c|c|c|}
\hline \multicolumn{2}{|c|}{ Model } & \multirow{2}{*}{\multicolumn{2}{|c|}{ Unstandardized Coefficients }} & \multirow{2}{*}{\multicolumn{2}{|c|}{$\begin{array}{c}\text { Standardized } \\
\text { Coefficients }\end{array}$}} & \multirow[b]{3}{*}{ Sig. } \\
\hline & & & & & & \\
\hline & & B & \multirow{2}{*}{$\begin{array}{l}\text { Std. Error } \\
.069\end{array}$} & \multirow[t]{2}{*}{ Beta } & \multirow{2}{*}{$\begin{array}{l}\mathbf{T} \\
13.010\end{array}$} & \\
\hline 1 & (Constant) & .900 & & & & .000 \\
\hline & Membership & .629 & .027 & .890 & 23.128 & .000 \\
\hline 2 & (Constant) & .421 & .064 & & 6.612 & .000 \\
\hline & Membership & .373 & .029 & .528 & 12.884 & .000 \\
\hline & Altruistic Love & .385 & .033 & .484 & 11.810 & .000 \\
\hline 3 & (Constant) & .452 & .054 & & 8.376 & .000 \\
\hline & Membership & .354 & .025 & .501 & 14.406 & .000 \\
\hline & Altruistic Love & .287 & .030 & .361 & 9.452 & .000 \\
\hline & Vision & .149 & .020 & .227 & 7.583 & .000 \\
\hline 4 & (Constant) & .207 & .046 & & 4.504 & .000 \\
\hline & Membership & .298 & .019 & .421 & 15.707 & .000 \\
\hline & Altruistic Love & .265 & .023 & .334 & 11.771 & .000 \\
\hline & Vision & .185 & .015 & .283 & 12.439 & .000 \\
\hline & Commitment & .116 & .011 & .202 & 10.758 & .000 \\
\hline 5 & (Constant) & .104 & .028 & & 3.696 & .000 \\
\hline & Membership & .253 & .012 & .358 & 21.767 & .000 \\
\hline & Altruistic Love & .228 & .014 & .287 & 16.728 & .000 \\
\hline & Vision & .152 & .009 & .232 & 16.698 & .000 \\
\hline & Commitment & .135 & .007 & .234 & 20.675 & .000 \\
\hline & Hope/Faith & .148 & .009 & .211 & 15.917 & .000 \\
\hline 6 & (Constant) & .099 & .020 & & 4.874 & .000 \\
\hline & Membership & .192 & .010 & .272 & 19.069 & .000 \\
\hline & Altruistic Love & .205 & .010 & .258 & 20.261 & .000 \\
\hline & Vision & .152 & .007 & .232 & 22.941 & .000 \\
\hline & Commitment & .128 & .005 & .222 & 26.816 & .000 \\
\hline & Hope/Faith & .160 & .007 & .227 & 23.303 & .000 \\
\hline & Productivity & .082 & .007 & .134 & 11.111 & .000 \\
\hline
\end{tabular}

\section{Conclusion and Recommendations}

\subsection{Main Conclusions}

The findings indicate the most significant dimensions of spiritual leadership in the Iranian healthcare industry. Each dimension of spiritual leadership has a positive relationship with spiritual leadership; among the dimensions, membership has the most significant relationship with spiritual leadership. It can be stated that a spiritual leader in the Iranian healthcare industry can motivate and inspire their followers to have a high willingness to work, enabling the organization to achieve organizational goals. Therefore, this fact can direct managers of Iranian healthcare facilities to engage employees with spiritual leadership.

\subsection{Managerial Implications}

It is worthwhile mentioning that by considering the results for each dimension of spiritual leadership, managers can encourage employees to perceive the organizational vision, to increase their faith in the organization, to perceive their work as meaningful, and to improve their organizational commitment and membership. Consequently, employees will be more involved with the organizational goals. In other words, this study is beneficial for managers in the Iranian healthcare industry as the results could help them to achieve positive 
outcomes such as higher employee productivity, greater employee commitment, meeting organizational goals. Also, managers can be more successful in their careers through implementing spiritual leadership.

\subsection{Academic Contribution}

The results of this study show that model of this study which is in the line with the introduced model by Fry in 2003 can be implemented in the Iranian healthcare industry. Therefore, the authors of the present research recommend that this model should be tested in other industries in future research in order to provide further contributions to this research area.

\subsection{Limitations}

This study has several limitations. First, the employees were reluctant to complete the questionnaires because of time constraints and a lack of willingness to reveal their personal opinions. Second, there was a lack of cooperation from some managers in terms of enabling the distribution and completion of the questionnaires. Third, this study has focused on employees of some healthcare centers in Tehran, Iran, which restricts the ability to generalize the findings to other cities, cultures, and industries.

\section{References}

Aydin, B., \& Ceylan, A. (2009). A research analysis on employee satisfaction in terms of organizational culture and spiritual leadership. International Journal of Business and Management, 4(3), 159. http://dx.doi.org/10.5539/ijbm.v4n3p159

Chegini, M. G., \& Nezhad, Z. F. (2012). The effect of spiritual leadership and other elements on employees' empowerment of Iran's bank: Case study of Guilan Province. African Journal of Business Management, 6 , 8420-8434.

Coakes, S. J., \& Steed, L. (2009). SPSS: Analysis without anguish using SPSS version 14.0 for Windows, John Wiley \& Sons, Inc.

Conger, J. A. (1999). Charismatic and Transformational Leadership in Organizations: An Insider's Perspective on These Developing Streams of Research. Leadership Quarterly, 10(2), 145-179. http://dx.doi.org/10.1016/S1048-9843 (99)00012-0

Fairholm, G. W. (1996). Spiritual leadership: Fulfilling whole-self needs at work. Leadership \& Organization Development Journal, 17(5), 11-17. http://dx.doi.org/10.1108/01437739610127469

Femke, G., Peter, S., Kenneth, L., \& Doris, J. (2003). Transformational leadership effects on teachers' commitment and effort toward school reform. Journal of Educational Administration, 41(3), 228-256. http://dx.doi.org/10.1108/09578230310474403

Freeman, G. (2011). Spirituality and Servant Leadership: A conceptual model and research proposal. Emerging Leadership Journeys, 4(1), 120-140.

Fry, L. W. (2003). Toward a theory of spiritual leadership. The Leadership Quarterly, 14(6), 693-727. http://dx.doi.org/10.1016/j.leaqua.2003.09.001

Fry, L. W. (2005). Toward a theory of ethical and spiritual well-being, and corporate social responsibility through spiritual leadership. Positive Psychology in Business Ethics and Corporate Responsibility, 47-83.

Fry, L. W., \& Matherly, L. L. (2006). Spiritual leadership and organizational performance: An exploratory study. Tarleton State University-Central Texas.

Fry, L. W., Hannah, S. T., Michael, N., \& Fred, O. W. (2011). Impact of spiritual leadership on unit performance. The Leadership Quarterly, 259-270. http://dx.doi.org/10.1016/j.leaqua.2011.02.002

Fry, L., \& Nisiewicz, M. (2013). Maximizing the triple bottom line through spiritual leadership. Stanford: Stanford University Press.

Giacalone, R. A., Jurkiewicz, C. L., Giacalone, R. A., \& Jurkiewicz, C. L. (2003). Toward a science of workplace spirituality. Handbook of workplace spirituality and organizational performance (pp. 3-28).

Mahmood, A., Bodla, H. A., \& Rizwan, Q. D. (2013). Role of Spiritual Leaders in Enhancing Employee's Performance.

Malone, P., \& Fry, L. W. (2003). Transforming schools through spiritual leadership: A field experiment. Meeting of the Academy of Management, Seattle, WA. 
Nelson, B. A. (2008). Spiritual leadership in healthcare College of Education and Behavioral Sciences Greeley. University of Northern Colorado. Doctor of Education.

Pfeffer, J., Giacalone, R., \& Jurkiewicz, C. L. (2003). Business and the spirit. Handbook of workplace spirituality and organizational performance.

Reave, L. (2005). Spiritual values and practices related to leadership effectiveness. The Leadership Quarterly, 16(5), 655-687. http://dx.doi.org/10.1016/j.leaqua.2005.07.003

Semercioz, F. (2011). The Relationship Spiritual Leadership and Issues of Spirituality and Religiosity: A Study of Top Turkish Managers. International Journal of Business and Management, 6(4), 136-145.

Snyder, C. R., \& Ingram, R. E. (2000). Handbook of Psychological Change: Psychotherapy Processes \& Practices for the 21st Century. New York, Wiley.

Strange, J. M., \& Mumford, M. D. (2005). The origins of vision: Effects of ref lection, models, and analysis. The Leadership Quarterly, 121-148. http://dx.doi.org/10.1016/j.leaqua.2004.07.006

Usman, A., \& Danish, R. Q. (2010). Leadership Spirituality in Banking Professionals and Its Impact on Organizational Commitment. International Journal of Business and Management, 5.

Yaghoubi, N. M., Moloudi, J., \& Banihashemi, S. (2010). The Relationship between Spirituality Leadership and Empowerment. American Journal of Scientific Research, (12), 180-186.

Yusof, J. M. (2011). A Multidimensional Approach in the Relationship between Spiritual Leadership and Job Satisfaction: A Conceptual Framework. 2nd International Conference on Business and Economic Research (2nd ICBER 2011).

\section{Copyrights}

Copyright for this article is retained by the author(s), with first publication rights granted to the journal.

This is an open-access article distributed under the terms and conditions of the Creative Commons Attribution license (http://creativecommons.org/licenses/by/3.0/). 